\title{
Replies to Niko Kolodny, Debra Satz, and Steven Wall
}

\author{
T. M. Scanlon ${ }^{1}$
}

Published online: 30 September 2019

(C) Springer Nature B.V. 2019

I am grateful to Niko Kolodny, Debra Satz, and Steven Wall for their careful and probing comments on my book, which leave me much to think about. Here are some preliminary responses.

Reply to Niko Kolodny

The examples that first led me to think of the form of objectionable inequality that I call violations of Equal Concern involved unequal provision of public services by municipal governments. My hypothesis was that these were cases in which a government has an obligation to provide a benefit, such as street cleaning or repaving, or broadband access, but not necessarily to provide that benefit at a specific level, as long as it is above a certain minimum. Failure to meet this minimum level of provision is a non-comparative wrong, but I suggested that it is a comparative wrong to provide the benefit, above this minimum, at a higher level to some than to others without some adequate justification for doing this. The element of discretion in the level of benefit that provided above the minimum level seems to me to create space for comparative wrongs. ('Discretionary' seems to me the apt description rather than 'supererogatory.')

Unequal provision can be justified. It may be impossible, for example, to supply better broadband access in a certain area, or there may be some reason, such as the needs of a research center, to provide better access in another area. Kolodny suggests that in such cases equal benefit is the default, which is required unless there is some justifying difference between the recipients. I do not disagree with this way of putting the matter, but it seems to me that what the justifying differences he lists have in common is that they show that the differences in benefit can be justified in a way that gives equal weight to the interests of all the recipients. The fact that a policy cannot be justified in this way is what makes it open to the objection I am

T. M. Scanlon

scanlon@fas.harvard.edu

1 Harvard University, Cambridge, USA 
discussing. This is what led me call the relevant requirement "Equal Concern" rather than "equal treatment," since unequal treatment can be unobjectionable when it is justified in the right way.

As I noted (Scanlon 2018: 21), the label, "Equal Concern" can be misleading, insofar as it suggests that the wrongfulness of unequal treatment lies in the attitudes of the agents in question. Unequal provision of benefits often arises from prejudice, such as racial prejudice, but it can take other forms, such as preferential treatment for political allies or friends of government officials. I meant to distinguish the underlying wrong of unjustified unequal provision of benefits, which is common to these cases, from the diverse attitudes that may explain this wrong, which themselves may be open to moral objection of the kind I discuss in Chapter 3, on status inequality.

As Kolodny suggests, 'favoritism' seems an appropriate term for this class of wrongs. But, as his examples show, that term also applies to a wider range of cases, including ones in which the underlying wrong is not comparative. Failure to prosecute crimes committed by certain people may constitute objectionable favoritism, even if crimes by others are not being prosecuted, perhaps because no such crimes have been committed. This policy might reflect excessive concern for the interests of those who are not prosecuted, but the underlying wrong in such cases would be non-comparative-simply the failure to apply the law correctly.

The same thing is true in at least some cases in which crimes are committed by members of two groups, but members of one group are prosecuted while members of the other group are let off, or punished less severely. This policy may reflect objectionable attitudes toward members of the two groups. But the underlying objection to what is done is non-comparative - a failure to do what the law requires in at least one of these cases. This is one way to interpret the complaint of the student in Kolodny's example who is denied an extension. She is asking, "How can it be true that he qualifies for an extension under the announced policy and I do not?"

There can, however, be cases of unequal application of a law or policy in which the underlying objection is comparative. Suppose it is unclear what counts as an excuse under the announced policy about extensions. Perhaps an interpretation of the rule that supported granting the extension and an interpretation that ruled this out would each be defensible in both cases. If so, granting an extension to one student but not the other could be an objectionable failure to apply the policy evenhandedly even if neither were a clear violation of the law.

Unequal application of a law may be a form of objectionable inequality that I should add to my list. But it is different from the cases that I call violations of Equal Concern. Those are cases in which a policy is justified by the benefits it brings to individuals in certain positions and in which greater benefits of this kind are supplied to some than to others. Cases of uneven application of a law need not be like this. The point of having deadlines for papers is not to give students benefits of the kind that are conferred to some by giving extensions. Granting extensions to some students can be objectionable when it involves giving their interests inappropriate weight-that is to say, taking their interests to justify departures 
from the rule that they do not actually justify-but the problem in such cases is not that they are given unequal weight. ${ }^{1}$

I agree with Kolodny that objections to inequality based on the requirement of Equal Concern are frequently made but have not been well understood. There are open questions about how when this requirement applies and why. Generalizing from the examples that occurred to me, I suggested in my book that the requirement applies when an agent has an obligation of a certain kind to each of a group of people - an obligation to supply some benefit, but not at a specific level. It seemed to me that governments can have obligations of this kind to their citizens, although it is not clear exactly which benefits governments are obligated to supply. It seems to me that parents have obligations to benefit their children that give rise to similar objections to unequal treatment. The idea that these objections depend on specific obligations seemed to me to explain why demands of equal concern do not require one to contribute equally to various aid programs. Although one has a general duty to make such contributions, this does not arise from obligations to all of the potential beneficiaries. Promises generally involve obligations to do specific things, so failures to fulfill them are generally non-comparative wrongs. But if I have promised simply to benefit to each member of some group in a certain way to some degree, then I might be open to objection if I provide more of this benefit to some than to others without any justification for doing so.

Kolodny is correct that my analysis of equality of opportunity presupposes that institutions that create "positions of advantage" to which special benefits are attached require justification. (My analysis of objections to inequality of income, in Chapter 9, has a similar presupposition.) This requirement of justification for inequality is different from that involved in the idea of Equal Concern, since the primary rationale for having these positions of advantage is not the benefits they involve for those who occupy them, and the positions are not created as a way of fulfilling an obligation to provide such benefits.

The potential objection that drives the need for what I call institutional justification is a comparative one: an objection to the fact that some are given the benefits that go with these positions while others are not. An objection to a violation of Procedural Fairness is a claim of maladministration: that the institution is not operating in the way that its justification requires. The objectionable effects of such maladministration are frequently comparative: that one person gets the job that should have been given to someone else. But as Kolodny points out, a person who was denied a position for which she was qualified would have such a complaint of maladministration even if no one else got the job. If, on the other hand, the employer simply ignored a person's application that person would have a (noncomparative) complaint of being denied what I called due consideration (Scanlon 2018: 51), whether or not anyone else gets the position.

Kolodny asks, reasonably, for a clearer account of the basis of the requirement of Substantive Opportunity. I will try to spell out what I had in mind and relate this to

\footnotetext{
1 So my shift, which Kolodny notes, between "equal weight" (21) and "appropriate weight" (19) was a slip on my part. In the cases I was thinking of there, appropriate weight was equal weight, but "appropriate" covers a wider range of cases than I intended.
} 
his interesting examples. Even in an economy with no "positions of advantage," being employable may require certain basic skills. If gaining the means of life depends on being employed, it is a serious objection to a society if some people in it have no way of acquiring these basic skills, hence no way of securing a livelihood other than perhaps by stealing. This seems to me to support the idea that the state has the obligation that I cited as recognized in the New Jersey Constitution, to provide all children with an education that equips them to participate in the economy. This obligation of the state to each citizen triggers the requirement of Equal Concern, to fulfill it to the same degree for all. But what must be equal here is what the state provides: it should not provide more for some than for others above the required minimum. If, however, the additional training that some parents can provide for their children raises the bar, so that those who lack it are frozen out of the job market, this has the effect of raising that minimum, requiring the state to do more for these others in order to meet its basic obligation, not merely to satisfy Equal Concern.

Now suppose that the economic system includes positions to which special benefits are attached. This inequality requires justification, and suppose that this is provided by the fact that having these positions benefits those who are worse off, provided that the positions are filled by individuals with the requisite skills. It seems objectionable if these positions are available only to those who grew up in families that were rich enough to provide them with the training required to gain these skills. Being excluded from these desirable positions may not be as bad as being excluded from the job market altogether. But having these positions be the province of a special class seems to me objectionable.

These positions of advantage are not, of course, available to all. They are restricted to those with the relevant abilities. This restriction follows from the justification for having the positions in the first place: only if they are filled by people with these skills will they bring the benefits that justify having them, which flow to the unskilled as well. ${ }^{2}$ But there is no similar justification for excluding those whose families cannot afford the needed training. ${ }^{3}$ So something like what Kolodny calls Equal Potential follows from a general requirement that no one be excluded from positions of advantage together with the justification for filling these positions in a way that has the effects that justify them. This explanation does not provide an argument for that requirement, but I hope to have at least made its appeal somewhat clearer.

Equal Potential is not a corollary of the requirement of Equal Concern. Like the weaker demand in the case of a society without unequal positions, it states an obligation which, according to Equal Concern, the state must (absent some justification) fulfill to the same degree for all. It could be fulfilled by preventing

\footnotetext{
${ }^{2}$ Note that this justification applies only to the benefits included in the position itself, such as greater education, more satisfying work and perhaps greater salary. As I say in Chapter 3, if in addition to these benefits those who occupy these positions have special social status this would be an objectionable.

3 This responds to the question raised by Hayek (1960: 89), about why advantages that parents confer on their children through their genes should be less open to objection than advantages conferred by their wealth.
} 
richer families from giving their children an advantage, by providing poorer children with whatever is needed to compete with children of the rich, or by making criteria of selection insensitive to the extra training that the rich can provide. As Kolodny observes, the first seems unacceptable and the second very expensive. As I say in my book, in the case of higher education in the United States there is something to be said for the third option. I will return to this possibility in my reply to Debra Satz.

Kolodny observes that Substantive Opportunity seems oddly focused on opportunities for employment and education leading to employment, and he asks why there is not a similar objection to other ways in which rich families can give their children better lives. The answer, I believe, lies in the strategic role of money as the means of access to goods in general, and earned income as a primary means of gaining this means. Procedural Fairness and Substantive Opportunity are conditions on the justifiability of inequalities in earned income and other employment-related benefits. Transfers by gift or inheritance are of course another form of income, and a different source of inequality. What I say about this in my book is that although parents cannot be barred from spending their money to aid their children, there is no reason why the resulting income should not be taxed like income from any other source.

\section{Reply to Debra Satz}

Debra Satz observes that the link between inequality of income and wealth and the other objections to inequality that I mention is "contingent." It is not a settled question, for example, "how high combatting income and wealth inequality should be on our list of social priorities." If these empirical connections are not strong, she says, then the emphasis on inequality of wealth and income may be misplaced.

I largely agree. In my concluding chapter I say that my view leads to a kind of egalitarian priority for the worst off. What the combined egalitarian reasons of the kind I describe support most strongly are measures to alleviate the plight of those who are subject not only to unjustifiable inequality of incomes but also status inequality, lack of equal opportunity, lack of political power, and unequal provision of public services.

I would qualify her observation slightly in two ways, however. First, I do believe that current income inequality is objectionable apart from its consequences. It is unfair because of the unjustifiable mechanisms that produce it. Second, these mechanisms produce inequality not only by enabling the very rich to become and remain very rich, but also by holding down the incomes of lower and middle classes. We have reason to object to mechanisms of both of these kinds, and objections to the latter may be stronger, in many cases.

So I agree that there are trade-offs between different kinds of egalitarian concern, and that some can be more urgent than others. And as I say in Chapter 1, I also agree that the pursuit of equality can be less important than other concerns. Raising millions out of abject poverty is more important than preventing some rich people from getting even richer by setting up hedge funds, for example, insofar as these are independent of one another. But I do not have a general explanation of how to assess these tradeoffs. 
I was led to my view about the requirement of Equal Concern simply by thinking about examples of when inequality seemed objectionable and when it did not, and trying to generalize from these cases as best I could. Arguing in this way is unavoidable, but risky, because examples, whether imagined or real, have many features that one may be overlooking, or influenced by even though one is not aware of this. But here is what I was thinking.

Contrary to some of my Canadian friends, I think that if the state is fulfilling its obligation to make health care up to a high enough level available to all of its citizens, then it is not objectionable for some families to buy health insurance providing more than this, as long as their doing so does not interfere with the health care available to others. But if the state, which has the same obligation to all its citizens, provided better health care for some than for others, this would be prima facie objectionable, as a policy that, it would seem, could only be justified by giving greater weight to the interests of some than the comparable interests of others. On the other hand, if the national government were to have an adequate national health insurance policy, it is not so clear that it would be objectionable if some state were to introduce a plan that gave more. This would reflect a collective decision by the citizens of that state to spend more on health care than on other things. Since that particular state is not obligated to provide health care to residents of other states, this policy need not be justified on the basis of any comparative assessment of the interests of its residents and the interests of others.

Earlier, I said that allowing a private market in health care beyond the level that a government provides would be unobjectionable provided that it did not compete with and thereby reduce what is available in the state program. As Satz suggests, Kanye West and Kim Kardashian's hiring private firefighters would be objectionable for this reason if they hire away firefighters from public employment. But suppose they flew in fire fighters from Nova Scotia on their private jet. Would the fact that they thus got better protection from the fire be objectionable? At least not, it seems to me, on grounds of what I am calling Equal Concern.

To sharpen the point, instead of Kardashian and West, consider a couple whose income is only average for the area, who have lobbied unsuccessfully to get the county to raise taxes to hire more firefighters in order to be ready for wild fires. After losing this campaign, they save up their own money to buy out of state fire insurance that will pay to bring in outside firefighters if needed. If, as a result, their house survives a fire that destroys many other homes, I find it difficult to see this as objectionable inequality. This suggest to me that our reaction to the original example of Kardashian and West has to do with two things: possible interference with publicly provided fire protection and the broader effects of extremely wealthy people being able to opt out of the public provision of benefits.

Satz discusses two objections to allowing richer citizens to provide buy higher levels of the services such as health care and particularly education. One objection is that if richer citizens have no need for public services they will be unwilling to support the level of these services that is owed to all. A related, but distinct worry, is that if the rich are allowed to separate themselves from the poor, with whose lives they have little contact, this will make them not only less willing to support measures that the poor need, but even unaware of the needs and life circumstances 
of the poor, and therefore more willing to accept ideas such as that poor people are lazy and undeserving. I agree with these points, which I discuss in my chapters on status inequality and on political fairness. These objections raise two questions, a practical question of what is to be done in response to them and a theoretical question about how they fit into the framework of objections to inequality that I have presented.

The underlying problem in these cases is the prevalence of certain inegalitarian attitudes of indifference to the interests of those who have less and consequent unwillingness to support policies needed to serve these interests adequately. Insofar as such attitudes are likely consequences of income inequality, they provide an additional objection, beyond those I have listed, to institutions that generate this inequality. Unlike Satz, however, I would not deny people the opportunity, if they have more money, to spend it on extra services for themselves and their families, such as private schools or higher level health insurance. What we can do is to make such expenditures less inviting, by providing public services at a sufficiently high level, and not to encourage them by, for example, making these expenditures tax deductible. As Satz observes, avoiding the development of such inegalitarian attitudes is also a legitimate consideration in other policy choices, such as decisions regarding housing policy and the location of public amenities. It provides a reason, for example, to have parks and other recreation facilities that will draw people from different areas together rather than separate facilities in different neighborhoods.

I have said that inegalitarian attitudes of indifference to the interests of others are open to objection on grounds of their consequences-that they undermine support for policies that justice requires. And it is a reason against other policies that they foster these attitudes, leading indirectly to these further effects. Beyond this, however, there is the question of whether these attitudes are objectionable in themselves or, rather, whether the prevalence of the corresponding egalitarian attitudes is a form of equality that is valuable in itself. This is a plausible egalitarian thesis that that was missing from my discussion.

I am pleased that Satz mentions the points in my chapters on equality of opportunity about moralism and about fact that equality of opportunity even if attained would not be a justification for the inequalities that result from it. It is also important to recognized that equality of opportunity has not been achieved, and is impossible to achieve fully. Differences between the families that children grow up in-not only differences in wealth and income but especially in values and "parenting styles" - affect their development in ways that it is impossible to erase But it is important to do the things we can to provide Substantive Opportunity, including things that Satz mentions such as increasing the quality of public schooling, integrating schools by race and class, and providing free high quality preschool.

Another step that I suggest in my book is limiting the factors on which admission to universities depends, eliminating some that give special advantage to children from richer families, such as advanced placement courses, foreign travel and internships. Eliminating these factors would leave a larger number of applicants who were ranked as equally qualified, and I suggest using a lottery for choosing among them. Satz does not reject this possibility, but she worries that it involves a 
trade-off between the goals of excellence and fairness. Given the difficulty of discerning who is genuinely promising, highly talented individuals may be screened out in the lottery.

This is certainly a possibility, but there is also a different trade-off, which I discuss. What I call Procedural Fairness requires that individuals be selected for positions of advantage based solely on factors indicating their likely success in advancing the aims that justify having these positions. But whether something is a factor of this kind depends on what these aims are and how the institution in question is organized to promote them. Being able to read French or to write computer code is a relevant factor if these abilities are presupposed by the courses offered in a university but not if training of these kinds is part of what is offered. This means there is a trade-off between designing a curriculum that is maximally efficient and one that is more inclusive.

Another measure that Satz suggests is "lowering the stakes" by making less depend on going to a top-ranked college. I agree with this, but would also suggest lowering the stakes in a different way. Following Joseph Fishkin (2014), I argue that it Is unfair to make so much of a person's life prospects depend on the abilities she demonstrates at an early age, which depend, among other things on the choices that she has made at this early stage, in the circumstances in which she was placed, about what to take an interest in. The goals of fairness to individuals and of making the most use of human talents would both be better served by a system that gave individuals more second chances.

Reply to Steven Wall

Am I a relational egalitarian? As Seven Wall notes, the objections to inequality that I discuss "all presuppose some form of relationship or interaction between the unequal partners." But this does not mean, as he goes on to say, that when inequality is objectionable this is so because of its "impact on the relations between people." In my view, inequality can be objectionable because of its effects, including but not limited to effects on people's attitudes toward one another, but it can also be objectionable because of the institutions that produce it.

One form of objectionable inequality, which I discuss in Chapter 3, occurs when some people in a society are widely regarded as inferior to others-less desirable neighbors or co-workers, and as not appropriate candidates for positions of expertise or authority. Racial discrimination is an obvious example, and there are many others. It is a bad thing for a person to be subject to such discriminatory attitudes. They are therefore objectionable intrinsically as well as because they lead to inequality of other kinds. The intrinsic objection seems to me an egalitarian one: it is an objection being regarded by others as inferior, not just an objection to being denied certain opportunities.

Violations of Equal Concern can arise from objectionable attitudes, such as racial discrimination. But the wrong of violating Equal Concern consists in the fact that the benefits owed to all citizens are being provided in a way that could be justified if the interests of all were given equal weight, not in the attitudes that give rise to this policy.

I also argue that unequal incomes can be objectionable when the institutional mechanisms that produce them cannot be justified in the right way. This, again, is an 
egalitarian objection: it is an objection not simply to being badly off (a person can be badly off for many reasons) but to unjustifiably receiving a share of the benefits of social cooperation that is less than other participants are receiving.

So I can agree with Wall that "a political society is rightly ordered in virtue of its being a society of equals" in which "each member of the society is treated, and viewed by others, as a member of equal standing with the rest." But the two parts of this condition-the equal treatment part and the "viewed by others" part—seem to me to be independent of one another.

According to one familiar conception of political fairness, political institutions are fair, and the results they lead to are legitimate, if, first, all citizens have the same rights to speak, to vote, and to hold office and, second, citizens have equal ability to exercise these rights by taking part in the political process. As Wall notes, the idea of equal ability is difficult to specify, but the central idea is that access to the means of attaining political office or influencing public policy should not depend on a person's wealth and income. The idea behind this conception is that a political system should provide a suitable framework for discussion and advocacy through which citizens form their preferences about governmental policy and a mechanism of political decision-making that is sensitive to the preferences they express and not more sensitive to the preferences of some than those of others.

The current political system in the United States does not fulfill this condition. Political scientists Larry Bartels (2008: 263) and Martin Gilens (2005: 781) point out that when the policy preferences of the rich are opposed to those of poorer citizens, the rich almost always prevail. The examples they give include such questions as raising the minimum wage, sending troops to Haiti, requiring employers to provide health insurance, allowing gays to serve in the military, whether the Civil Rights Act should cover discrimination in employment, and transfer of funds from defense spending to programs to aid poor people.

One of the main points in Chapter 6 of my book is that although a lack of equal access to means of political persuasion is a problem in the current US, unequal access is not the problem in all of these cases. The issues at stake in at least some of these cases, such as discrimination in employment and allowing gays to serve in the military, are questions of basic justice, not ones that, in a well-functioning political system, should not be settled by sensitivity to the balance of conflicting preferences. The problem in these cases is not the lack of equal ability to influence but rather one of excessive ability to influence, i.e. the ability to influence legislators to vote for policies that they should not support. (The analog in the case of equality of opportunity would not be rich parents providing their children with benefits that give them an unfair advantage in competing for admission to universities but rather rich parents bribing university administrators to give their children preference.)

Equal access to the means of political participation, if we could attain it, would not solve these problems. An example I cite is the persistent refusal of the New Jersey Legislature to fulfil the constitutional mandate of "thorough and efficient education" for all children. Gerrymandering and other forms of unfairness in the political system have no doubt played a role in this. But if a sufficiently large number of voters would rather have lower taxes than provide state funding for poorer school districts, then the problem could persist even these forms of 
unfairness were removed and all citizens had equal access to the means of political influence. The lack of concern for the interests of poorer citizens, which Satz observes as a consequence of economic inequality, plays an important role here.

In saying this I am moving some way from what Wall calls the equal opportunity principle toward what he calls the instrumental principle, according to which "factors that give some greater political influence than others are objectionable only when they impede the proper functioning of the political process." He writes, "If the rich can use their economic power to capture the political process and make it serve their interests at the expense of the common good, then we have reason to either eliminate their economic power or prevent it from having these effects. By contrast, unequal access to other factors or means that are relevant to attaining office or influencing policy that do not have these effects, would not be objectionable, and could even be valuable."

What I have said indicates that I agree with Wall that factors that give some greater influence than others can be objectionable because they "impede the proper functioning of the political process" in ways other than simply by being unequal. I also agree that factors such as judicial review that help to insure proper functioning of the political process can be justified even though they involve departures from equal ability to influence outcomes.

The crucial question, however, concerns the idea that departures from equal access are objectionable only when they "impede the proper functioning of the political process," or, to put the matter slightly differently, the question is in some cases whether the proper functioning of a political system requires a sensitivity to the views of citizens that depends on their having equal opportunity to influence outcomes. The examples I mentioned in which influence was excessive because it impeded the proper functioning of the political process involved questions of basic rights and justice. Wall mentions a broader class of cases, in which the rich use their greater influence to "make the political process serve their interests at the expense of the common good." I also cite such cases (Scanlon 2018: 84-85). But there can be alternative conceptions of the common good, each of which is defensible. So it is very plausible to suppose that when such questions are at issue a well-functioning political system should be sensitive to the views of different citizens about the common good and should give them equal opportunity to advocate for their particular views. So I hope Wall might agree that the idea of equal opportunity plays some role in the idea of a well-functioning political system even if we may disagree about how wide a role this is.

Wall raises challenging questions about my rejection of the idea that inequality of income can be justified on the ground that it is deserved because of differences in marginal productivity. This is a subject that I find puzzling. So I am grateful to him for raising it although I remain skeptical.

As Wall notes, I acknowledge that if one member of a productive partnership makes an aspect of their product that contributes more to its market value than the aspects due to the other partner, this makes it reasonable that the former partner should get a greater share of their profits. But I do not accept the general counterfactual test according to which participants in any productive enterprise should be rewarded in proportion to the ratio between the differences that adding or 
subtracting a unit of their contributions would make to the value of what they produce.

As an example, I consider a case in which one worker directs the activities of the others, and adding or subtracting an hour or a day of this director's work makes a bigger difference to their collective output than adding or subtracting the same amount of the time of one of the other workers. Just having the position of director may already involve inequality. It may be more pleasant work, and carries a form of authority. If the position requires no special ability, then perhaps workers should be selected for it by a lottery. If so, then this inequality may be unobjectionable. But should the person in this position also receive greater pay, given the greater impact of her work? Would it be unfair if she did not? I do not see that would be.

Drawing on a suggestion of Thomas Hurka (2011: 166), Wall offers a principle of reward in accord with contribution: "Those who benefit others more, deserve more, other things equal." It is plausible to say that those who benefit others more deserve more praise and gratitude (at least if they benefit others for the right kind of reason.) But do they also deserve greater income? I am not so sure.

It does seem objectionable that grade school teachers are paid so much less than advertising executives, or even philosophy professors. The contribution principle might explain why this inequality is objectionable, but one could also object to it on other grounds. The analysis of unequal income that I offer in Chapter 9 of my book (which does not rely on desert) would imply that this inequality is objectionable because there is no adequate justification for the institutional mechanisms that produce these differences in pay. Another thing that is objectionable about this situation is the status differences involved: given the social importance of what teachers do, it is objectionable that the status and esteem of being a teacher is so much less than is attached to these other professions. This is an idea of desert, and is closer to the contribution principle. But what does this have to do with income? This claim about desert would have implications about income only given the assumption that income is the appropriate expression of social esteem and gratitude. This may be true in our society to a large extent, but does not seem justifiable. (Scanlon 2018: 122)

Suppose that being a school teacher were seen, because of its social importance, as having equal or greater status than being a professor or an executive, and as being just as much a career that people aspire to and feel proud of having. If this were so, would it be unfair if teachers and professors were paid the same? I do not think so.

Reflecting on this leads me to rethink my reaction to the example of the partners who make different parts of a joint product. The sense that an unequal division of the profits would be appropriate in that case does not seem to be an instance of the contribution principle, since it seems independent of the social value of what they are producing. What is at work in that case seems to me on further reflection to be less an idea of desert than an intuition about the bargain it would be reasonable for the partners to strike, given the differing market values of their contributions and the differing alternative options that are therefore available to them. 


\section{References}

Bartels, L. (2008). Unequal democracy: The political economy of the new gilded age. Princeton: Princeton University Press.

Fishkin, J. (2014). Bottlenecks: A new theory of equal opportunity. Oxford: Oxford University Press.

Gilens, M. (2005). Inequality and democratic responsiveness. Public Opinion Quarterly, 69, 778-796. Hayek, F. (1960). The constitution of liberty. Chicago: University of Chicago Press.

Hurka, T. (2011). Drawing morals: Essays in ethical theory. Oxford: Oxford University Press.

Scanlon, T. (2018). Why does inequality matter?. Oxford: Oxford University Press.

Publisher's Note Springer Nature remains neutral with regard to jurisdictional claims in published maps and institutional affiliations. 